\title{
Jogar e compreender a Química: ressignificando um jogo tradicional em didático
}

Playing and understanding chemistry: Reinterpreting a traditional game for educational use

Ana Carolina Rosa da Silva Paloma Lopes de Lacerda1 ${ }^{2}$ Mariadas Graças Cleophas_ ${ }^{3}$

\section{Resumo}

Não se pode negar a importância que vem sendo dada ao uso dos jogos didáticos no contexto escolar. Seguindo esta perspectiva, este artigo divulga uma investigação realizada sobre as contribuições de um jogo para o ensino de propriedades coligativas. $\bigcirc$ jogo foi aplicado em uma turma do $2^{\circ}$ ano do ensino médio, pertencente a uma escola do sudeste piauiense. A pesquisa relatada é de cunho qualitativo. Utilizamos questionários para a coleta de dados, além da observação direta sobre os aspectos fenomenológicos surgidos durante a aplicação do jogo. Os resultados revelaram que o uso de jogos didáticos não consiste numa prática comum para os sujeitos analisados, e as suas concepções sobre a utilização do jogo em questão nos fizeram inferir que a atividade lúdica proposta contribuiu com o fortalecimento de diferentes aspectos que são necessários para a melhoria do processo de ensino e aprendizagem da Química.

Palavras chave: jogo didático; ensino de química; atividades lúdicas; propriedades coligativas

\section{Abstract}

The importance of using educational games in the school context cannot be denied. Therefore, this article describes a study about the contributions of a game for teaching colligative properties. The game was used with a second-year class in a high school located in southeast Piauí, Brazil. It is a qualitative study; it used questionnaires for data collection and direct observation about phenomenological aspects that emerged during the application of the game. The results showed that the use of educational games is not common for the subjects observed. Their views on that use lead us to infer that the proposed playful activity has contributed to strengthen distinct aspects needed to improve the teaching and learning process in Chemistry.

Keywords: educational game; chemistry teaching; playful activities; colligative properties

\footnotetext{
${ }^{1}$ Universidade Federal do Vale do São Francisco | carolina.rsilva20@gmail.com

${ }^{2}$ Universidade Federal do Vale do São Francisco | palomalopes36@gmail.com

3 Universidade Federal da Integração Latino-Americana | maria.porto@unila.edu.br
} 


\section{Introdução}

O ato de jogar é uma atividade praticada desde que a humanidade iniciou seu processo de civilização (ORTIZ, 2005). Contudo, os jogos utilizados neste longo período de tempo serviam apenas como um instrumento de diversão, e não estavam relacionados ao contexto educacional. Em seu ponto máximo, o mesmo seria apenas um veículo que servia para melhorar o raciocínio lógico, ou mesmo para formular e estruturar estratégias de guerra, ou combate aberto. É inegável admitir que os jogos apresentam um papel de destaque, seja na educação, ou fora dela. Atualmente, a utilização dos jogos didáticos como aporte para a compreensão de conceitos envolvendo a Química é objeto de investigação de diversos pesquisadores na área de Educação Química (SOARES et al. (2003); SOARES et al. (2006); SANTOS et al. (2009); CASTRO e COSTA (2011); FACETOLA et al. (2012); LACERDA et al. (2013); SILVA et al. (2015), entre outros). Há ainda muito para ser investigado no que se refere à relação entre a função instrucional do jogo didático/pedagógico e o ganho cognitivo dos sujeitos.

Para Martinez et al. (2008), o jogo é uma ferramenta educacional que serve para auxiliar os processos de ensino e aprendizagem na sala de aula, em diferentes níveis e em diversas áreas do conhecimento. Acreditamos, assim como Facetola et al. (2012), que o uso de jogos educacionais no ensino de ciências é uma prática já estabelecida, cujo objetivo é auxiliar os alunos a compreender ou revisar o conteúdo ministrado de forma lúdica, porém efetiva.

De acordo com Sá et al. (2007), nas últimas décadas, muitas pesquisas e reflexões têm sido realizadas na busca de estratégias para lidar com as dificuldades na aprendizagem de conteúdos científicos pelos alunos. Igualmente, Castro e Costa (2011) afirmam que um dos desafios atuais do ensino de Química é fazer uma ligação entre o conhecimento ensinado e o cotidiano dos alunos. Sem essa ponte, os alunos tornam-se desestimulados e acabam considerando a Química uma disciplina difícil, com módulos/temas muito complexos e que exigem muita memorização e questionamentos acerca da necessidade de sua aprendizagem. É fundamenta elaborar estratégias que aproximem o conhecimento científico do cotidiano dos alunos, pois "o conhecimento em Química configura-se como um valioso instrumento para a efetiva formação do cidadão, pois poderá permitir-Ihe uma leitura mais crítica e consciente acerca do mundo a sua volta" (COSTA e SOUZA, 2013, p. 109), e neste viés instrumental, a construção de jogos didáticos surge como valiosas estratégias que podem contribuir perante a formação de sujeitos capazes de ler o mundo de forma crítica e consciente, porém, sem perder de vista à motivação e alegria de (re)descobrir o mundo ao seu redor.

Segundo Campos (2003), a utilização dos jogos didáticos representa uma alternativa viável e interessante, pois tende a preencher muitas lacunas deixadas pelo processo de transmissão-recepção de conhecimentos. Assim, enxergamos que, com a utilização das atividades lúdicas em sala de aula, tais como os jogos didáticos, os professores e alunos têm a possibilidade de construir essa ponte e enveredar por outros caminhos que levem à aprendizagem, driblando o tradicionalismo, ainda contemporaneamente operante, encontrado no ensino de Química. Logo, as inúmeras problemáticas inerentes ao aprendizado da Química podem ser amenizadas com a diversificação de estratégias didáticas, tais como a utilização e aplicação de jogos didáticos em sala de aula. Ou seja, a ludificação dos processos de ensino e aprendizagem da Química apresenta elevado potencial para desenvolver competências e habilidades cognitivas. 
Miranda (2001) complementa ainda que vários objetivos distintos podem ser atingidos com a utilização de jogos didáticos em sala de aula, a citar, os relacionados à cognição (desenvolvimento da inteligência e da personalidade, fundamentais para a construção do conhecimento); à afeição (desenvolvimento da sensibilidade e da estima e atuação no sentido de estreitar laços de amizade e efetividade); à socialização (simulação de vida em grupo); à motivação (envolvimento da ação, do desafio e mobilização da curiosidade) e à criatividade. Cunha (2012) assegura ainda que os jogos didáticos desenvolvem habilidades tais como o raciocínio, o trabalho em equipe, além de proporcionar uma maior interação aluno-professor e possibilitar um maior desenvolvimento intelectual e pessoal do aluno.

O uso de jogos didáticos pode ser aplicado como um método alternativo para desenvolver na sala de aula temas atrelados à Química de maneira dinâmica, evitando aulas exaustivas e monótonas (SATURNINO et al., 2013). Neste viés, Jann (2010) afirma que os jogos didáticos entraram no cenário atual devido a sua praticidade, pois são facilmente manipuláveis em salas de aula, apresentam custo reduzido, favorecem o processo de aprendizagem de uma maneira estimulante, contribuem no desenvolvimento das relações sociais, aguçama curiosidade e, por fim, instigam o desejo em adquirir mais conhecimento. Contudo, é importante destacar que o jogo não pode ser considerado o fim, mas o eixo condutor de um conteúdo didático específico, resultando em um empréstimo da ação lúdica para a aquisição de informações (KISHIMOTO, 1996).

Como vemos, o uso da ludicidade no ambiente escolar já é uma prática estabelecida por muitos profissionais. Entretanto, Gomes e Friedrich (2001) revelaram que os jogos no ambiente educacional nem sempre foram associados aos princípios didáticos, pois havia um pensamento de que o uso dos mesmos estava meramente associado ao prazer, logo, eles assumiam pouca importância para a formação do estudante. No cenário atual, esta ideia já não é mais preponderante, haja vista que a mesma já vem sendo bastante difundida por meio de pesquisas em âmbitos nacional e internacional, as quais defendem 0 enriquecimento cognitivo proporcionado pelos jogos quando atrelados ao processo de ensino e aprendizagem. No entanto, defendemos que ainda é importante difundir e divulgar outras estratégias didáticas pautadas no lúdico que possam ser utilizadas em sala de aula, tais como o uso de histórias em quadrinhos, júri simulado, jogos digitais, caçapalavras, álbum de figurinhas, teatro químico, entre inúmeras outras, pois, certamente, estas variantes lúdicas contribuirão para uma ressignificação no modo de ensinar Química.

No que se refere à apropriação do lúdico no ambiente escolar por parte do professor, acreditamos que esta é uma ação que deve ser incentivada ainda na sua formação inicial. Os cursos de licenciatura devem promover ensinamentos basilares que permitam aos futuros professores condições de utilizar diferentes estratégias didáticasem sala de aula. A ideia é construir um diálogo sobre a necessidade contínua de proporcionar a diversificação metodológica. É importante que os professores saibam utilizar corretamente a ludicidade com meio de fortalecer ou construir aprendizagens em Química, levando-se em consideração, a importância do planejamento, execução, acompanhamento e avaliação da atividade lúdica proposta. Porto (2015) assegura que é fundamental que o professor tenha ou aprenda a ter uma "postura lúdica" no ambiente escolar, pois a existência dessa postura é capaz de fornecer inúmeros benefícios para a aprendizagem dos seus alunos, tais como favorecer a inteligência emocional, motivação, senso crítico, capacidade autoavaliativa, estímulo à criatividade, socialização, raciocínio lógico, etc. 
Já Felício (2011) defende a importância da "intencionalidade lúdica". Para ela, esta seria uma atitude de caráter intencional do professor, voltada e orientada ao equilíbrio do aspecto prazeroso e pedagógico da atividade lúdica (seja ela qual for) a ser desenvolvida por ele. Ampliando para o contexto da Química, os jogos didáticos são alternativas viáveis para abordar conteúdos de diferentes complexidades cognitivas de uma forma divertida e dinâmica, expandindo, assim, caminhos que possam favorecer distintas aprendizagens. Contudo, sabemos que o jogo didático não resolverá todos os problemas encontrados no ensino de Química, mas, certamente, ele contribuirá para amenizar a problemática relacionada aos aspectos motivacionais, a falta da diversificação didático-metodológica em sala de aula, a passividade do aluno (pois o torna mais ativo em seu processo de aprendizagem), entre outros aspectos. No entanto, é imprescindível que o jogo seja utilizado de modo correto, ou seja, levando-se em consideração os objetivos didáticos que se desejam alcançar, estando estes atrelados à aprendizagem dos alunos, além de uma seriedade didático-metodológica (planejamento, execução, acompanhamento e avaliação). O jogo didático, sendo uma estratégia lúdica, apresenta em seu escopo uma seriedade que tem como foco desenvolver habilidades cognitivas em seus jogadores. Ou seja, estrategicamente, ele deve ser lúdico, mas, didaticamente, é fundamental que ele seja sério e eficaz sob o ponto de vista cognitivo.

O objetivo deste trabalho é relatar todas as observações e resultados extraídos perante a elaboração e aplicação de um jogo didático, voltado para o desenvolvimento cognitivo sobre o conteúdo 'propriedades coligativas. O jogo "A velha da Química" foi construído tendo como prioridade a utilização de materiais de baixo custo e de fácil acesso, possibilitando, assim, a sua replicação, tanto para o professor, quanto para o aluno. O jogo foi utilizado por alunos do $2^{\circ}$ ano do ensino médio de uma escola da rede de ensino da cidade de São Raimundo Nonato (PI). Por meio desta estratégia lúdica, foi possível direcionar os alunos a um debate crítico-reflexivo sobre o seu aprendizado e suas concepções acerca do tema proposto imbuído no jogo, permitindo, ao mesmo tempo, relembrar o conteúdo, ou, até mesmo, sanar lacunas referentes à sua compreensão. Como veremos, muitos questionamentos foram levantados sobre o conteúdo em si e também sobre o propósito do jogo, conforme será descrito adiante.

\section{Os jogos na perspectiva lúdica e vygotskyniana}

A busca por estratégias didáticas que contribuam para que processo de ensino e aprendizagem se torne motivador tem sido uma das grandes dificuldades encontradas por parte dos professores de níveis fundamental e médio (SOUZA e NASCIMENTO JUNIOR, 2005). Atualmente, várias estratégias têm sido utilizadas por educadores com o propósito de fazer emergir resultados positivos a partir do seu uso. Neste contexto, os jogos situam-se como estratégias pedagógicas com amplas perspectivas de eficácia em relação aos seus benefícios para a aprendizagem. Para Hessel (2002), o jogo é um subsídio que pode proporcionar o aprender com prazer, onde através do mesmo se facilita a busca de significados. Estes significados devem ser previamente planejados e articulados pelo professor, o qual deve atuar como um mediador de todo o processo de ensino e aprendizagem proposto. Neste sentido, o trabalho de Gouvêa e Suart (2014, p. 31) corrobora este entendimento, pois, para estas autoras, "na sala de aula, o professor deve ser um mediador que auxilia o aluno a usar suas habilidades cognitivas". 
Diante do exposto, podemos perceber que as atividades lúdicas, principalmente os jogos, estão sendo vistas como potentes recursos auxiliares para o processo de ensino e aprendizagem das Ciências. A estimulação, o desafio, a colaboração, o interesse, a concentração e a motivação são algumas benesses proporcionadas pelos jogos que podem, efetivamente, auxiliar os alunos perante o desenvolvimento de suas habilidades cognitivas. Cunha (2004) já preconizava que o "lúdico deveria impulsionar os trabalhos escolares, pois, sendo um recurso didático educativo, poderia ser utilizado em diversos momentos, tais como a apresentação de um conteúdo, a ilustração, a revisão de assuntos abordados em aula e até mesmo como avaliação de conteúdos já desenvolvidos" (CUNHA, 2004, p.28). Para Fialho,

A exploração do aspecto lúdico, pode se tornar uma técnica facilitadora na elaboração de conceitos, no reforço de conteúdo, na sociabilidade entre os alunos, na criatividade e no espírito de competição e cooperação, tornando esse processo transparente, ao ponto que o domínio sobre os objetivos propostos na obra seja assegurado (FIALHO, 2007, p. 16).

Como foi citado anteriormente, o lúdico pode apresentar-se de diferentes formas e métodos. Porém, para sua utilização em um contexto educacional, é necessário uma "ação lúdica", termo este definido por Soares (2004), como sendo uma forma divertida, seja qual for o contexto linguístico em que ela está inserida, desconsiderando o objeto envolto na ação. A apropriação e utilização de atividades lúdicas, tais como os jogos, perante o ensino é amplamente incentivada pelos documentos oficiais que orientam sobre a educação básica, como se observa na citação abaixo.

Os jogos e brincadeiras são elementos muito valiosos no processo de apropriação do conhecimento. Permitem o desenvolvimento de competências no âmbito da comunicação, das relações interpessoais, da liderança e do trabalho em equipe, utilizando a relação entre cooperação e competição em um contexto formativo. O jogo oferece o estímulo e o ambiente propícios que favorecem o desenvolvimento espontâneo e criativo dos alunos e permite ao professor ampliar seu conhecimento de técnicas ativas de ensino, desenvolverem capacidades pessoais e profissionais para estimular nos alunos a capacidade de comunicação e expressão, mostrando-lhes uma nova maneira, lúdica e prazerosa e participativa, de relacionar-se com o conteúdo escolar, levando a uma maior apropriação dos conhecimentos envolvidos (BRASIL, 2008, p.28).

Quanto aos pressupostos teóricos que possam dar aporte perante a explicação dos benefícios cognitivos oferecidos pelos jogos didáticos, quando aplicados em sala de aula, existem inúmeros. Desse modo, encontramos na literatura vários trabalhos sobre jogos, e alguns se sustentam, teoricamente, no desenvolvimento cognitivo, defendido por Piaget (CAVALCANTI e SOARES, 2009; TONELLI et al., 2011; BIANCHINI et al., 2012; CAVALCANTI et al., 2012), outros defendem suas ideias apoiados na teoria da aprendizagem significativa de Ausubel (FREITAS e SALVI, 2007; BARBOSA et al., 2008; CASTRO e COSTA, 2011), alguns autores discutem seus trabalhos ancorados na Escola de Vygotsky (DOMIMGOS e RECENA, 2010; MIRANDA et al., 2010; FACETOLA et al., 2012; MESSEDER et al., 2013; RODRIGUES e FURTADO, 2013), e, finalmente, existe trabalho que recorre ao construtivismo radical de 
Maturana para explicar como são proporcionadas aprendizagens por meio do uso do jogo didático ou pedagógico (PORTO, 2015).

Sob o viés da Escola de Vygotsky, é possível estabelecer algumas analogias entre sua teoria e o uso do lúdico na educação, pois os jogos ou brinquedos consistem em instrumentos que possibilitam à criança agir "numa esfera cognitiva" (VYGOTSKY, 2007, p. 111). Segundo esteteórico do ensino como processo social,o aluno exerce um papel ativo no processo de aprendizagem, pois apresenta condições de relacionar o novo conteúdo a seus conhecimentos prévios. Neste contexto, o professor torna-se responsável por conduzir o desenvolvimento de zonas de progresso proximal, ou seja, possibilitar condições e situações para que o aluno transforme e desenvolva em sua mente um processo cognitivo mais significativo. Assim, percebe-se que o educador tem um papel importantíssimo na aprendizagem do aluno, pois, ao utilizar os jogos didáticos, ele contribui para que os alunos desenvolvam funções mentais que podem viabilizar o seu aprendizado.

Deste modo, os professores, ao criarem situações didático-metodológicas favoráveis à autonomia da aprendizagem, promovem um espaço para o confronto de visões, de opiniões, discussões abertas, debates, livre reflexão e reorganização dos saberes (VYGOTSKY, 1982). Na visão sociointeracionista do autor, o processo de ensino e aprendizagem acontece, principalmente, na relação que existe entre aquele que aprende e aquele que ensina, e entre os demais envolvidos nesse processo. Para Vygotsky (1998), o desenvolvimento cognitivo se dá pela interiorização de instrumentos e signos. Dito isto, podemos inferir que o jogo didático tem a função de servir como instrumento e, por meio dele, surgem alguns signos, tal como a linguagem falada. Pois percebe-se que, ao utilizar os jogos, eles fazem emergir vários diálogos entre os participantes. Estes diálogos surgem em prol da resolução dos problemas ou desafios impostos pelos jogos (sendo mais facilmente resolvidos quando ocorrem através da interação social).

Assim, podemos concordar que o uso de jogos didáticos promove a interação social dentro do ambiente escolar, pois é impossível jogar sem que haja uma teia de diálogos entre os jogadores que levem à argumentação. Dessa maneira, acreditamos que o conhecimento provém desse resultado, ou seja, o desenvolvimento cognitivo é produzido pelo processo de internalização que se dá pela interação social. Vygotsky et al. (1988) acreditava que as características individuais, e até mesmo suas atitudes mais íntimas, estão impregnadas de trocas com o coletivo, ou seja, mesmo aquilo que consideramos como mais individual de um ser humano, ele foi, certamente, construído a partir de sua relação com o outro indivíduo. Essa mesma ideia defende Wallon (1989), de que o ser humano é organicamente social. O filósofo Johan Huizinga (2007) afirma que existe uma necessidade das pessoas se relacionarem de forma lúdica e ficcional, como mecanismo de sobrevivência dentro da sociedade.

Segundo Tezani (2006), o jogo cria uma situação de regras que proporcionam uma zona de desenvolvimento proximal entre os alunos (ZDP). Vale ressaltar que a zona de desenvolvimento proximal (ZDP) é uma zona intrínseca de cada aluno/indivíduo. Neste caso, os professores têm a tarefa de implantar, em suas aulas, diferentes atividades, a citar, por exemplo, o uso dos jogos didáticos ou pedagógicos, de modo que estas possam atingir diferentes direcionamentos, visando, assim, proporcionar possibilidades distintas para que cada aluno alcance a sua ZDP. Para o autor, o jogo representa a articulação entre o desejo, a afetividade, a inteligência e os processos de apropriação do conhecimento e o avançar das zonas de desenvolvimento. A interação social que os jogos favorecem aos envolvidos 
durante uma atividade lúdica, tende a proporcionar distintas aprendizagens que devem ocorrer na ZDP.

\section{Delineamento metodológico}

O delineamento metodológico deste trabalho foi dividido em etapas, visando uma melhor sistematização e apresentação dos dados.

\section{Foco da Pesquisa}

A pesquisa é de natureza qualitativa. Para Angers (1992), neste tipo de pesquisa é mais importante haver anotações para descrever e compreender uma determinada situação, do que números para enumerar frequência de comportamento. Alguns dados foram coletados a partir dos questionários pré-teste e pós-teste e, posteriormente, tabulados e analisados sistematicamente. Deste modo, os dados coletados foram categorizados de acordo com as similitudes encontradas nas respostas atribuídas aos questionários aplicados aos participantes da pesquisa.

\section{Lócus da Pesquisa e sujeitos}

A pesquisa foi realizada em uma escola da rede de ensino da cidade de São Raimundo Nonato, localizada no sudeste do Piauí. Foi selecionada uma turma do $2^{\circ}$ ano do ensino médio, composta por 12 alunos, com adolescentes na faixa etária entre 15 e 17 anos de idade. A aplicação do jogo teve duração de 70 minutos.

\section{O jogo e suas regras}

O jogo nomeado "A velha da Química" foi uma adaptação do jogo da velha tradicional. Dentro do enquadramento proposto por Chateau (1984). Este enquadramento, visa nortear as tipologias das regras para um determinado jogo. Assim,o jogo "A velha da Química" teve suas regras originadas por imitação, ou seja, foram regras resgatadas de uma atividade mais antiga e adaptada para uma mais recente.

O jogo proposto foi construído em proporções maiores, sendo adaptado a fim de ser utilizado em tamanho proporcional aos alunos. Com isto, não perdemos a essência do jogo tradicional (o qual geralmente é jogado com auxílio de caderno, folhas de papel, ou até mesmo sendo riscado no chão) para um mundo mais concreto, de forma que o aluno pudesse interagir por completo, utilizando o seu corpo como parte integrante do jogo. "A velha da Química" foi construído com materiais de fácil acesso e baixo custo, tais como tecido chita, cola, Iona, TNT e cartolina. Vale salientar que o jogo e as regras foram rigorosamente testados, antes de colocá-los em contato com os alunos. Com isto, tentou-se evitar que problemas ocorressem durante a aplicação da atividade lúdica, envolvendo o jogo.

O jogo, fisicamente, é composto por um tabuleiro medindo $180 \mathrm{~cm} \times 120 \mathrm{~cm}$. Possui cartões contendo perguntas e respostas acerca do conteúdo "propriedades coligativas". Foram elaboradas várias questões envolvendo o conteúdo utilizado no jogo com situações vivenciadas pelos alunos em seu cotidiano, ou seja, muitas questões eram contextualizadas. Também foram inseridas questões envolvendo cálculos, logo, todos os integrantes tinham à 
mão papel e caneta, facilitando, assim, o processo de estruturação das respostas. O jogo foi elaborado para ser utilizado por duas equipes, contendo cinco integrantes em cada, onde quatro destes, foram designados como "peças humanas" para o tabuleiro, representando assim $\circ \underline{X}$ e o $\underline{O}$ existentes no jogo da velha tradicional, e o quinto integrante, foi nomeado como "auxílio universitário", cujo objetivo era ajudar a equipe durante as perguntas consideradas difíceis.

No entanto, o "auxilio universitário" só poderia intervir duas vezes durante a partida. Desta maneira, estabeleceu-se que o pedido de auxílio apenas seria solicitado caso surgissem obstáculos durante a partida, ou seja, os mais difíceis para a tomada de decisão e, consequentemente, a resolução do problema. Foram confeccionadas e entregues algumas fitas coloridas para cada equipe, visando distinguir os seus integrantes. A fita de cor azul representava as peças humanas do tipo "으", e a de cor verde representava as peças do tipo " $\underline{X}$ ".

Ao iniciar a partida, um integrante da equipe contrária escolhia uma carta-pergunta e lançava a questão para a outra equipe. A equipe desafiada podia comunicar-se entre si em busca da resposta. Caso a resposta fosse correta, os "alunos peças" escolhiam uma "casa"para ser ocupada dentro do tabuleiro do jogo. No entanto, a cada resposta errada, a equipe era penalizada, passando a sua vez para a outra equipe.

\section{Aplicação e coleta de dados}

O processo envolvendo o jogo foi constituído de três etapas, sendo a primeira, a aplicação de um questionário que antecedeu o início da utilização do jogo, a segunda, a aplicação e observação direta sobre os aspectos fenomenológicos que emergiram por meio da atividade realizada, e, por fim, a terceira etapa, que consistiu na distribuição de um questionário pós-jogo. A participação dos alunos na atividade foi de natureza não obrigatória, estando em concordância com o preconizado por Caillois (1990), o qual orienta que o jogo deve ser uma atividade livre e voluntária.

\section{$1^{a}$ etapa: Questionário prévio}

Nesta etapa, foi elaborado um questionário constituído de cinco questões, sendo quatro de múltipla escolha e uma aberta (subjetiva); por meio dele, o aluno teve a oportunidade de descrever suas expectativas sobre a utilização do jogo didático em sala de aula.

\section{$2^{a}$ etapa: Aplicação do jogo}

Consistiu na aplicação do jogo "A velha da Química". Neste momento, antes de iniciar a partida, foram divididas as equipes e esclarecidas as regras do jogo. Ao todo, dez alunos se voluntariaram para participar da atividade lúdica. Foram formadas duas equipes contendo cinco integrantes. A formação das equipes se deu por livre escolha dos estudantes. Cada equipe elegeu seu "auxílio universitário", sendo este responsável por escolher um cartãopergunta e lançar a questão para a equipe oponente. Cada equipe foi representada por uma cor eapós o início da partida, apenas uma das equipes sairia vitoriosa. Vale destacar que o jogo foi aplicado em uma turma que já tinha visto o conteúdo sobre propriedades coligativas em sala de aula. 
$3^{a}$ etapa: Questionário pós-jogo

Este era composto por sete questões dicotômicas (do tipo sim ou não), contendo espaços para justificativas.

\section{Análise dos dados}

Os questionários aplicados foram analisados qualitativamente, e as respostas textuais foram analisadas fenomenologicamente, ou seja, foi fundamentada no fenômeno pesquisado (POUPART, 2012). Buscou-se, primeiramente, a compreensão fenomenológica dos significados obtidos a partir da aplicação do jogo. Desta forma, estávamos mais preocupados com os significados reais sobre os efeitos do jogo para a aprendizagem dos alunos, do que, necessariamente, com os fatos em si.

\section{Resultados e discussão}

\section{Questionário prévio e seus resultados}

A voluntariedade foi um aspecto devidamente respeitado durante a aplicação do jogo, tal como defendido por Huizinga (1980). Do total de alunos existentes na turma de $2^{\circ}$ ano, ou seja, $100 \%(n=12)$, apenas $83,34 \%(n=10)$ participaram voluntariamente da atividade. 0 jogo "A velha da Química" foi produzido e aplicado com o intuito de aprimorar e estreitar a relação dos alunos com a Química e, sobretudo, para contribuir no fortalecimento e/ou aprendizado do conteúdo abordado (propriedades coligativas).

A partir da coleta de dados obtidos com as respostas do questionário prévio, foi possível diagnosticar algumas dificuldades que seriam enfrentadas pelos alunos durante a etapa de aplicação do jogo, conforme demonstradas pelos Gráficos 1 e 2.

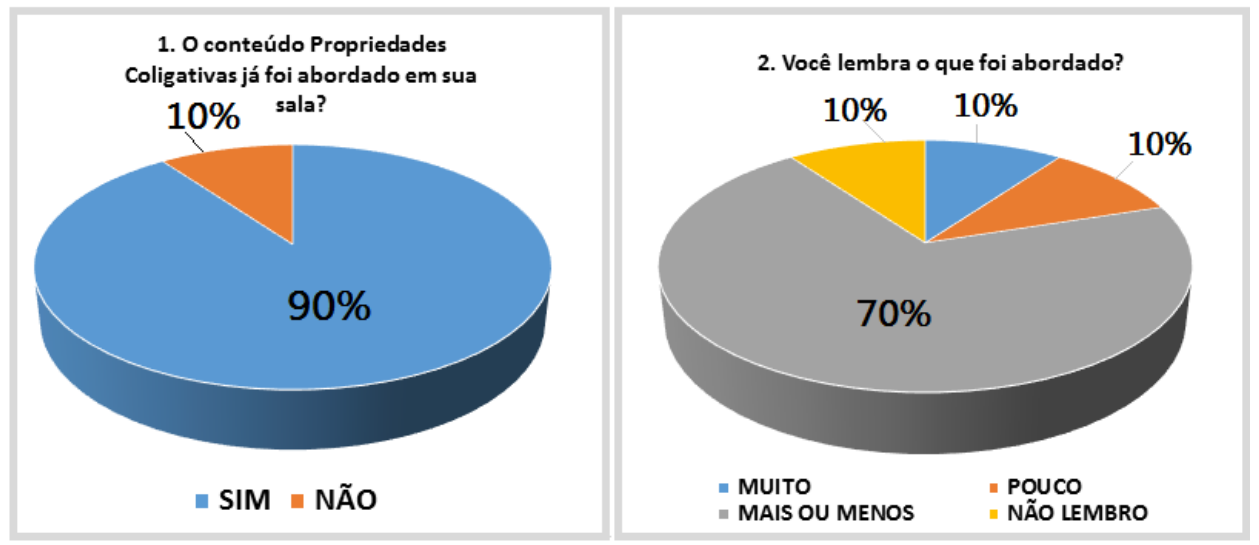

Gráfico 1 e 2: Respostas dadas pelos alunos às questões 1 e 2 do questionário prévio.

De acordo com o Gráfico 1, percebe-se que houve uma dicotomia das informações por parte dos alunos. Isto nos mostra que $90 \%(n=9)$ dos alunos afirmaram que o assunto foi abordado em sala de aula, já 10\% ( $n=1)$ alegaram não ter visto tal conteúdo. Este fato pode ser compreendido a partir da imaturidade dos alunos, pois, algumas vezes, é comum, em uma sala de aula, encontrar alunos que não "conseguem" lembrar os nomes dos conteúdos vistos, nem tampouco, conseguem atribuir uma relação entre os conceitos discutidos em sala de aula com a sua vivência cotidiana. 
Quando questionados acerca do que foi abordado em sala de aula, durante o desenvolvimento conceitual do conteúdo, 70\% $(n=7)$ dos discentes afirmaram recordar "mais ou menos" do que foi discutido em relação ao tema abordado no jogo. Algumas manifestações dos alunos sobre esta questão foram observadas, tais como: 'Meu Deus, eu já esqueci disso?', 'Nossa, eu não lembro muito', 'A minha nota foi baixa, isso mostra o quanto gostei do conteúdo', 'Me lembro quase nada'. Segundo Castro et al. (2005, p. 31), a "metodologia tradicional de ensino de Química na Educação Básica se destaca pela utilização de regras, fórmulas e nomenclaturas, gerando uma grande desmotivação entre os alunos". Certamente, a desmotivação é um fator relevante que compromete a aprendizagem dos alunos. O professor deve proporcionar diferentes situações didáticometodológicas que amenizem os aspectos não motivacionais em seus alunos. Neste viés, é muito importante para o processo didático, que o professor saiba explorar os conceitos científicos de forma motivadora, permitindo, assim, que os estudantes aprendam mais e melhor. E, seguramente, o uso de atividades lúdicas se torna uma opção com elevado potencial para auxiliar o professor na diversificação metodológica que o ambiente educacional tanto necessita.

A classificação quanto ao nível de dificuldade que os alunos atribuíram ao tema abordado é alarmante, pois $80 \%(n=8)$ deles afirmaram que o conteúdo "propriedades coligativas" é complexo.Já 20\% ( $n=2)$, classificaram como regular, e nenhum aluno considerou o conteúdo como fácil, tal como pode ser observado pela análise dos Gráficos 3 e 4.

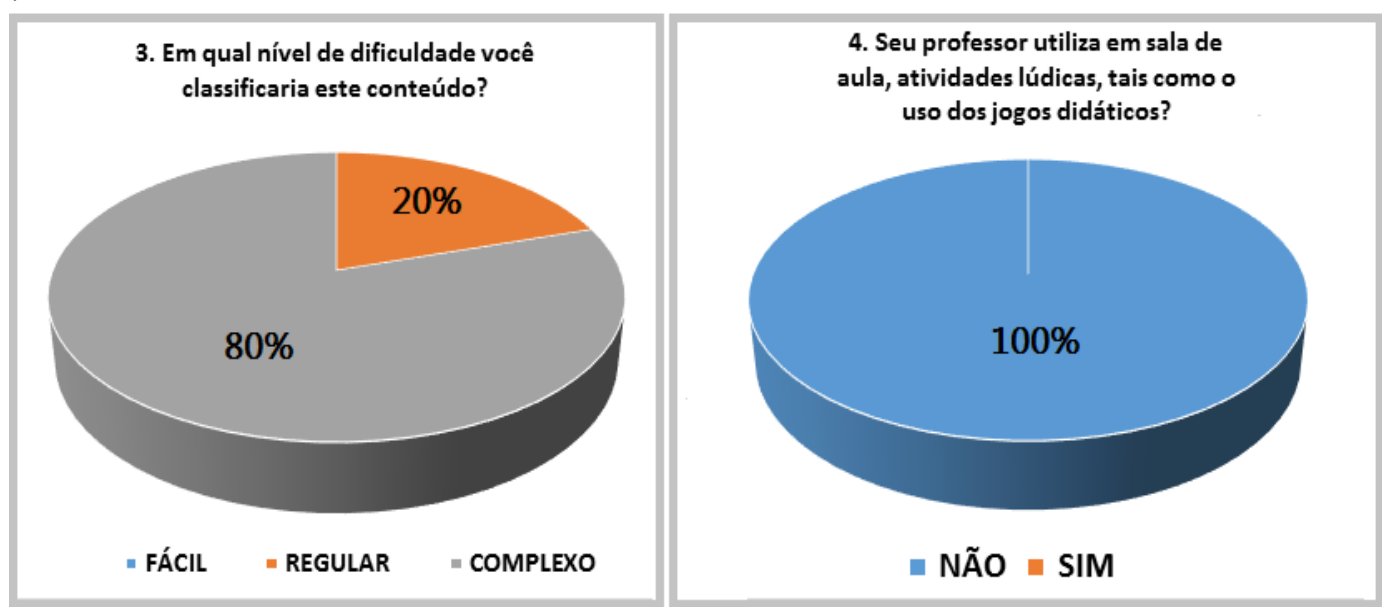

Gráficos 3 e 4: Respostas dadas pelos alunos às questões 3 e 4 do questionário.prévio.

O Gráfico 4, contendo dados referentes à Questão 4, mostra que estes alunos não estão sendo envolvidos em um ambiente escolar que proporciona práticas voltadas ao uso dos jogos didáticos; $100 \%$ dos participantes informaram que não têm acesso a um processo de ensino e aprendizagem que integre, regulamente, o uso de atividades lúdicas. Deste modo, podemos perceber que estes alunos desconhecem o efeito da construção social destas atividades para a sua formação (BROUGÈRE, 2002). Os benefícios dos jogos didáticos para o processo de ensino e aprendizagem são evidentes. Fialho (2007) argumenta que a exploração do aspecto lúdico pode se tornar uma técnica facilitadora na elaboração de conceitos, no reforço de conteúdo, na sociabilidade entre os alunos, na criatividade e no espírito de competição e cooperação, tornando esse processo transparente, a tal ponto que o domínio sobre os objetivos propostos na obra seja assegurado. 
Acreditamos que cabe ao professor promover uma diversificação metodológica em sua prática docente. Pois, ao inserir propostas pedagógicas, tais como estratégias pautadas no uso regular de jogos didáticos, ele estará contribuindo para instigar aspectos motivacionais de natureza intrínseca e extrínseca em seus alunos e, com isso, poderá favorecer o desencadeamento de distintas habilidades cognitivas em seus estudantes. Desse modo, o professor estará promovendo a construção de uma "vibelúdica" em prol da melhoria do processo de ensino e aprendizagem da Química em suas aulas, visto que vários benefícios em relação ao desenvolvimento cognitivo dos estudantes podem ser gerados a partir do uso de jogos didáticos ou pedagógicos (quando estes são estrategicamente bem elaborados). Logo, fica claro que o jogo pode ser usado como estratégia educacional para promover a construção significativa do conhecimento (FERRER, 2015).

O quinto item do questionário prévio foi subjetivo. Ele foi respondido por todos os alunos que participaram da atividade lúdica. Algumas respostas nos causaram surpresa, uma vez que nenhum dos alunos participantes tinha vivenciado alguma atividade desta natureza em sala de aula, o que nos revela a carência sobre a utilização de estratégias do tipo lúdico-didáticas para este público em questão. Em sua totalidade,os dados coletados para este item foram expressivos. O Quadro 1 exibe algumas respostas atribuídas pelos alunos. Vale salientar que, até aquele momento, nenhuma explicação tinha sido dada aos participantes, apenas tinha sido informado que eles teriam a oportunidade de utilizar um material lúdico em sua aula de Química sobre o conteúdo de propriedades coligativas.

Quadro 1: Repostas dos alunos ( $\mathrm{n}=10$ ) às perguntas abertas do questionário prévio aplicado.

\begin{tabular}{|c|c|}
\hline $\begin{array}{l}\text { Você gostaria de utilizar } \\
\text { jogos didáticos na sua } \\
\text { sala de aula? }\end{array}$ & $\begin{array}{l}\text { Qual sua opinião sobre usar um determinado jogo, que fosse } \\
\text { elaborado para contribuir com o seu aprendizado em sala de } \\
\text { aula? (Exemplos de alguns fragmentos) }\end{array}$ \\
\hline \multirow{5}{*}{$\begin{array}{c}\text { SIM } \\
(n=10,100 \%)\end{array}$} & $\begin{array}{l}\text { "Deixaria as aulas mais interessantes, legais, com mais interesse } \\
\text { no assunto, pois geralmente é muito complexo para mim Química } \\
\text { e física, e com isso facilitaria mais até o aprendizado". }\end{array}$ \\
\hline & $\begin{array}{l}\text { "Isso facilitaria mais o aprendizado da gente, diminuindo a } \\
\text { dificuldade que alguns têm em Química". }\end{array}$ \\
\hline & $\begin{array}{l}\text { "Seria mais dinâmico para nós e acho que teríamos mais interesse } \\
\text { na matéria". }\end{array}$ \\
\hline & $\begin{array}{l}\text { "Nós sairíamos da rotina cotidiana e seria um jeito novo de } \\
\text { ensinar um assunto antigo". }\end{array}$ \\
\hline & $\begin{array}{l}\text { "Eu não gosto muito de Química, tem muita decoreba, se eles } \\
\text { ajudarem a não ter que decorar, vai ser bom!" }\end{array}$ \\
\hline
\end{tabular}

Conforme visto no Quadro 1, os alunos apresentaram uma receptividade favorável à aplicação do jogo, evidenciando também alguns problemas rotineiros, extraídos a partir das manifestações, tais como 'o processo de decoreba' sobre os conteúdos, 'rotina', 'apatia com a Química', 'dificuldade de aprendizado acerca do que é ensinado pelo professor', 'eu não gosto de Química', entre outros. Quando questionados sobre "se gostariam de utilizar jogos didáticos em sua sala de aula", 100\% $(n=10)$ dos estudantes afirmaram que sim. Após a finalização da etapa de coleta dos dados com o questionário prévio, todas as regras do jogo foram devidamente explanadas aos alunos; posteriormente a isso, deu-se início ao jogo. Foram realizadas observações acerca da desenvoltura dos alunos durante a aplicação 
do jogo. Por meio destas observações, foi possível perceber uma falha sobre o tempo estimado para a sua aplicação em sala de aula (aula de 45 minutos), pois o processo de aplicação completa do jogo fez-se num período de tempo de 01 hora e 10 minutos (70 minutos). O aumento de tempo, relacionado a duração da atividade lúdica, se deu pelos inúmeros questionamentos dos alunos acerca do conteúdo inserido no jogo, por exemplo, alguns alunos tinham dificuldades conceituais sobre pressão de vapor, ponto de ebulição, soluções moleculares, pressão osmótica, etc. Talvez, por se tratar de um assunto complexo, sob os olhares dos alunos, e pelo fato de o jogo ser coordenado por cartões-perguntas, os participantes precisaram de mais tempo para ler e reler as perguntas e, desta forma, interagir com os integrantes de sua equipe de forma mais efetiva, visando a resolução dos problemas inseridos no jogo, por meio da interação e mobilização de saberes entre os participantes da atividade.

\section{Questionário pós-jogo e seus resultados}

A aplicação do jogo foi relevante sob diversos aspectos, pois foi possível avaliá-lo holisticamente, permitindo identificar possíveis erros de estruturação, além de verificar as dificuldades enfrentadas pelos alunos em relacionar e responder corretamente às questões abordadas. O jogo atuou como uma ferramenta importante para construção de significados, pois favoreceu que o aluno se tornasse mais ativo no processo de construção do seu próprio conhecimento. O jogo também serviu como instrumento pedagógico para analisar e avaliar um determinado período de ensino no qual se abarcou o conteúdo do jogo em sala de aula. Percebemos também que os alunos subestimaram o grau de dificuldade imposto pelo jogo, pois, para muitos, se tratava apenas de um "simples" jogo da velha. Mas, ao se deparar com novas regras e com a inserção dos objetivos didáticos, os quais foram planejados perante a adaptação do jogo tradicional, foi possível mostrar aos discentes que estas ferramentas lúdicas possuem, em sua essência, uma seriedade e um propositado disfarce, o qual tem a finalidade de transformar o complexo em algo mais assimilável e agradável, sob o ponto de vista cognitivo dos alunos. Assim, uma aprendizagem baseada numa perspectiva socioconstrutivista envolve a introdução do aluno em um mundo simbólico (neste caso, o simbólico foi materializado em formato de um jogo didático), o qual consiste de crenças conceitualmente organizadas e delimitadas por regras (BRUNER, 1995).

Também foram analisados os pontos positivos e negativos do jogo. Estes foram notados durante a aplicação da atividade, e também foram observados durante a coleta de dados, referente ao questionário pós-jogo. Nesta etapa, foi possível analisar de forma mais incisiva como o jogo pode ou não influenciar a aprendizagem do aluno. Com base nesta coleta, os dados estão apresentados no Quadro 2.

Através das respostas dos alunos, foi possível constatar os efeitos positivos do jogo "A velha da Química" para o fortalecimento da aprendizagem do conteúdo didático presente no jogo. No entanto, é importante destacar o posicionamento autocrítico dos alunos em relação ao jogo, pois alguns atribuíram suas dificuldades durante a execução do jogo a sua própria postura apática enquanto o professor ministrava sua aula expositiva sobre o conteúdo didático presente no jogo. 
Quadro 2: Respostas dos alunos ( $n=10)$ às perguntas abertas do questionário pós-jogo aplicado, contendo alguns exemplos de fragmentos das respostas dos alunos

\begin{tabular}{|c|c|c|c|}
\hline PERGUNTA & $\begin{array}{c}\text { SIM } \\
\text { (No de } \\
\text { respostas) }\end{array}$ & $\begin{array}{c}\mathrm{NA} \tilde{O} \\
\left(\mathrm{~N}^{\circ} \text { de }\right. \\
\text { respostas })\end{array}$ & $\begin{array}{c}\text { JUSTIFICATIVA } \\
\text { (Exemplos de alguns fragmentos textuais) }\end{array}$ \\
\hline $\begin{array}{l}\text { O jogo "A velha da } \\
\text { Química" funcionou como } \\
\text { instrumento de revisão, } \\
\text { consolidação e ampliação } \\
\text { do conhecimento? }\end{array}$ & 10 & - & $\begin{array}{l}\text { - "Ajudou muito mais no entendimento do } \\
\text { assunto"; } \\
\text { - "Muito bom, aprendi o que não sabia"; } \\
\text { - "É muito bom ter conhecimentos de outras } \\
\text { formas"; } \\
\text { - "Aumentou e tirou dúvidas sobre vários pontos } \\
\text { dento do assunto"; } \\
\text { - "Tinha 'coisa' que eu não tinha visto ainda, pois } \\
\text { faltei muitas aulas deste conteúdo". }\end{array}$ \\
\hline $\begin{array}{l}\text { O jogo promoveu uma } \\
\text { maior aproximação entre } \\
\text { você e seus colegas de } \\
\text { classe? }\end{array}$ & 10 & - & $\begin{array}{c}\text { - "Todos nós somos unidos. Mas, mesmo jogando, } \\
\text { nos fortalecemos como equipe"; } \\
\text { - "Sim, interagimos mais, falamos mais uns com os } \\
\text { outros". }\end{array}$ \\
\hline $\begin{array}{c}\text { O jogo auxiliou na } \\
\text { compreensão sobre o } \\
\text { conteúdo de } \\
\text { propriedades coligativas? }\end{array}$ & 8 & 2 & $\begin{array}{l}\text { "Sim. Mas tinha que lembrar dos conteúdos para } \\
\text { saber jogar, mas as perguntas já ajudavam a } \\
\text { recordar"; } \\
\text { "Tive dificuldade de relacionar o conteúdo com a } \\
\text { Química presente em nossas vidas"; } \\
\text { "Sim. Não sabia que esse assunto poderia vir } \\
\text { disfarçado de jogo, isso motivou!"; } \\
\text { "Faltei muitas aulas, o jogo clareou algumas coisas, } \\
\text { porém eu precisava ter noções sobre o conteúdo". }\end{array}$ \\
\hline $\begin{array}{l}\text { Você recomendaria o uso } \\
\text { desse jogo em outras } \\
\text { turmas, como forma de } \\
\text { ajudar na aprendizagem } \\
\text { dos conceitos } \\
\text { apresentados? }\end{array}$ & 10 & - & $\begin{array}{c}\text { - "Com certeza vai ajudar no estudo de muitos } \\
\text { assuntos"; } \\
\text { - "Assim como eu, eles irão gostar"; } \\
\text { - "Isso ajudaria bastante a compreender vários } \\
\text { assuntos químicos"; } \\
\text { - "É bom pra revisar para o ENEM!". }\end{array}$ \\
\hline $\begin{array}{l}\text { O jogo "A velha da } \\
\text { Química" precisa de } \\
\text { alterações? }\end{array}$ & 1 & 9 & $\begin{array}{l}\text { - "A questão do 'auxílio universitário', se ele não } \\
\text { souber do assunto, não ajuda em nada"; } \\
\text { - "Se não souber do assunto, complica!"; } \\
\text { - "Para mim está tudo bom". }\end{array}$ \\
\hline $\begin{array}{l}\text { Você gostou do jogo "A } \\
\text { velha da Química"? }\end{array}$ & 10 & - & $\begin{array}{c}\text { - "Aprendi, interagi com os demais colegas e discuti } \\
\text { sobre o conteúdo"; } \\
\text { - "Sim, é uma forma diferente de ver o mesmo } \\
\text { assunto". }\end{array}$ \\
\hline
\end{tabular}

Podemos considerar que a atividade lúdica desenvolvida em sala de aula foi avaliada pelos alunos como favorável para a aquisição e/ou fortalecimento de habilidades cognitivas, além da ressignificação sobre o conteúdo "propriedades coligativas". O jogo contribuiu para fomentar discussões, favorecer interações dialógicas entre os participantes durante o jogo, corrigir erros, exaltar os acertos, estreitar e enriquecer a mediação necessária na relação professor-aluno. 
Algumas respostas atribuídas ao questionário pelos alunos foram elucidativas e pontuais, pois, por meio delas, foi possível estabelecer uma associação entre a aceitabilidade e as concepções dos alunos em relação à atividade. Percebemos, mediante a relação dos alunos com o jogo didático utilizado, que pontos importantes tiveram destaques, proporcionando assim, circunstâncias que certamente contribuíram com a aprendizagem dos alunos, tais como o estímulo à criatividade e à criticidade; a revisão sobre o conteúdo; situações interacionistas entre os sujeitos; indícios de preenchimentos de lacunas existentes durante a construção do conhecimento em sala de aula (observadas pelo grande número de questionamentos realizados durante o jogo); tomada de decisão; raciocínio lógico, etc. Portanto, consideramos que o jogo desencadeou nos alunos uma postura mais ativa perante sua aprendizagem, evidenciando que sua utilização no contexto educacional pode favorecer situações que tornem o aluno responsável por sua aprendizagem, sendo necessário que, para isso, ele esteja imerso em situações de ensino que sejam capazes de promover a criatividade, o dinamismo, a espontaneidade e o prazer de brincar.

Entretanto, mesmo sabendo que era imprescindível que os alunos apresentassem certo conhecimento prévio sobre o conteúdo explorado no jogo, eles se sentiram "desconfortáveis" em alguns momentos durante a atividade, pois alguns alunos estavam certos de que, para jogar, seria necessário apenas o fator sorte. Tal fato, vai ao encontro do observado por Para Veloso e Sá (2009), pois para os autores, o jogo exerce um elemento de tensão importante, que significa o acaso, contudo, acredita-se que, ao planejar um jogo, não deve ser potencializado o fator sorte, pois isto, muitas vezes, mascara a atividade ao não favorecer que os objetivos didáticos traçados pelo professor sejam de fato atingidos. Ainda em relação ao aspecto sorte, Porto (2015) assegura que ela pode se tornar um fator excludente dos aspectos cognitivos do jogo, ou seja, ela deve ser cautelosamente dosada quando o jogo estiver em fase de elaboração.

Em relação à aceitabilidade dos alunos, bem como à interação destes com o jogo, foi condizente com a expectativa gerada durante a elaboração do mesmo. Desde o início da aplicação do jogo, os integrantes que optaram em participar da atividade manifestaram um grande entusiasmo com a experiência que seria vivenciada. Vale ressaltar que, durante a aplicação do jogo, todos os alunos reclamaram que o conteúdo "propriedades coligativas" tinha sido visto há bastante tempo e que estavam temerosos em não lembrar o assunto abordado em sala de aula. Apesar disso, os resultados foram satisfatórios, pois eles demonstraram que os alunos apresentaram boa desenvoltura frente à atividade lúdica desenvolvida, e, por meio dos inúmeros diálogos fomentados durante o jogo, as relações sociointeracionistas propostas por Vygotsky, puderam ser observadas, pois a interação e a construção argumentativa entre os alunos favoreceram a resolução dos problemas que estavam inseridos no jogo.

Acreditamos, assim como descrito por Viana e Sousa (2013), que os jogos podem contribuir com o sujeito cognoscente, à medida que os ajudam a formar conceitos, selecionar ideias e estabelecer relações interpessoais. Além disso, o jogo proposto contribuiu como material de revisão de conceitos, favoreceu o processo de alfabetização científica (pois aproximou os conhecimentos científicos adquiridos na escola com o cotidiano dos alunos), fortaleceu a aprendizagem e, ainda, pode ter auxiliado a superar obstáculos existentes na aquisição de conhecimentos sobre o conteúdo de propriedades coligativas. Prontamente, este tipo de atividade lúdica demonstrou apresentar elevado 
potencial para mediar o processo de ensino e aprendizagem, devendo, portanto, continuar sendo inserido na sala de aula como ferramenta que vise a (re)significação do conhecimento por parte dos alunos, além de ser um material prático, divertido, estimulante e dinamizador das aulas.

Contudo, para que os benefícios sejam realmente eficazes, sob o ponto de vista cognitivo dos alunos, é importante que o professor aja como facilitador da aprendizagem, pois cabe a ele planejar e conduzir os processos que medeiam as condições necessárias ao aprendizado do aluno (CLEOPHAS, 2016). No entanto, também se torna extremamente valioso para o processo de ensino e aprendizagem que o professor proponha aos alunos atividades em grupo, incentivando assim, que eles construam jogos didáticos sobre temáticas relacionadas à Química, uma vez que, ao construir e jogar os seus jogos e dos demais colegas, os alunos compreenderão melhor a Química.

Portanto, é importante que o professor exponha todos os objetivos da atividade lúdicodidática, em especial as regras do jogo didático (quando se tratar de um jogo), valorize as experiências e as manifestações de habilidades cognitivas dos seus alunos e que seja capaz de promover um feedback contínuo do desempenho dos alunos sobre o conteúdo imbuído na atividade lúdica, sanando assim, eventuais dúvidas ou corrigindo possíveis erros detectados durante a execução da atividade. Ao construir e aplicar um jogo didático, ele pode ser usado também para avaliar os resultados do que foi ensinado pelo professor em sala de aula sobre um determinado conteúdo, fornecendo desse modo, um panorama sobre o processo de ensino que foi adotado, pois ele evidenciará os pontos frágeis desse processo, indicando a necessidade de serem retomados pelo professor em sala de aula visando a correção de falhas na aprendizagem dos alunos.

De outra maneira, torna-se importante salientar que os jogos podem representar uma ótima estratégia lúdica para subsidiar o processo de ensino e aprendizagem, porém o mesmo deve ser utilizado com cautela pelos professores, e o seu uso não deve isentar outras estratégias ou recursos metodológicos que visem a melhoria da prática educativa. Neste viés, defendemos que o jogo didático nada mais é que um aporte metodológico para o processo de aprendizagem, ou seja, um recurso que favorece a tomada de decisão e que beneficia o processo de resolução de problemas, porém, mesmo com tantas vantagens já apontadas na literatura, ele, por si só, não é capaz de superar todos os obstáculos que existem na construção de diferentes conhecimentos científicos relacionados à química, precisando, portanto, de outros mecanismos didático-pedagógicos que possam auxiliar na ascensão destes construtos.

\section{Conclusão}

A aceitação e interação dos alunos com o jogo demonstrou que "A velha da Química" apresentou potencial como recurso útil para reforçar o conhecimento, corrigir erros conceituais, aproximar a química do cotidiano,fortalecer as relações interpessoais, sanar lacunas existentes no aprendizado dos alunos sobre o conteúdo "propriedades coligativas", entre outros benefícios. No momento da aplicação da atividade, foram observadas algumas dificuldades, tais como a duração total do jogo, alguns erros nas respostas dos cartõesperguntas, além da necessidade de delimitar tempos diferenciados para questões teóricas e questões que envolviam o uso de cálculos matemáticos para obtenção da resposta correta. 
As colocações ou indagações dadas pelos alunos durante a aplicação do jogo, observadas nos questionários, enfatizaram a capacidade que os jogos possuem de estimular naturalmente atitudes relacionadas à competição, interação e cooperação, tornando-se uma atividade diferenciada dentro do contexto escolar (sob o ponto de vista do sujeito aqui analisado), por ser dinâmica e agradável para todos os participantes, pois o lúdico favoreceu vários aspectos, tais como o prazer, a alegria, a competição(que foi ser explorada pelo professor de forma saudável), o desafio e a incerteza. O jogo contribuiu com o raciocínio e pensamento crítico do aluno e deu indícios da mobilização da inteligência coletiva (LÉVY, 1997), ou seja, os discentes utilizaram suas habilidades cognitivas de modo grupal, visando resolver os problemas ou desafios de forma coletiva, não individual, somando-se, assim, as habilidades e competências de cada participante em prol da superação dos desafios impostos no jogo - e, ainda, contribuiu para que os alunos estabelecessem relações entre o conteúdo abordado no jogo e o seu cotidiano.

Por fim, não podemos afirmar jamais que o jogo proposto foi um "construtor de conhecimento" isolado, mas é possível inferir que o mesmo fortaleceu e abriu um novo leque de oportunidades e alternativas de aprendizagem, tanto para os participantes, quanto para o professor da turma. Os resultados obtidos nesta pesquisa dialogam com Ferrer (2015 citando Winniccot e Prieto Figueroa, 1984), pois vimos que o jogo é um recurso didático essencial para a educação formal, uma vez que circunscreve uma série de atividades agradáveis, de curta duração, divertidas e regradas que fortalecem valores como o respeito, a tolerância, a responsabilidade e a solidariedade.

\section{Referências}

ANGERS, M. Iniciation pratique à la méthodologie des sciences humaines. Montreal: Centre Educatif et Culturel (CEC), 1992.

BARBOSA, R. C.; TAVARES, R.; SANTOS, J. N.; RODRIGUES, L. G.; ANDRADE, M. O jogo educacional como recurso digital e a aprendizagem significativa de gramática. XIX Simpósio Brasileiro de Informática na Educação (SBIE), 2008.

BARDIN, L. Análise de conteúdo. SP: Edições 70, p. 51, 2011.

BIANCHINI, L. G. B.; OLIVEIRA, F. N.; VASCONCELOS, M. S. Procedimentos no Jogo Virtual Colheita Feliz: Entre a Virtude e a Regra. ETD - Educ. Tem. Dig., v.14, n.1, p.1-21, 2012.

BRASIL. Ministério da Educação - Secretaria de Educação Média e tecnológica. Orientações Educacionais Complementares aos Parâmetros Curriculares Nacionais: Ensino Médio. Vol. 2: Ciências da Natureza, Matemáticas e suas Tecnologias. Brasília: MEC, 2008.

BROUGÈRE, G. Lúdico e Educação: novas perspectivas. Linhas Críticas, vol. 8, n. 14, 2002.

BRUNER, J. From joint attention to the meeting of minds: An introduction. In MOORE, C.; DUNHAM, P. J. (Eds), Joint attention: Its origin and role in development, pp. 189-203. Hillsdale, N. J.: Lawrence Erlbaum, 1995.

CAMPOS, L. M. L.; BORTOLOTO, T.M; FELÍCIO, A. K. C. A produção de jogos didáticos para o ensino de Ciências e Biologia: uma proposta para favorecer a aprendizagem. Caderno dos núcleos de Ensino, Botucatu, p.35-48, 2003. 
CASTRO, B. J.; COSTA, P. C. F. Contribuições de um jogo didático para o processo de ensino e aprendizagem de Química no Ensino Fundamental segundo o contexto da Aprendizagem Significativa. Revista Electrónica de Investigación en Educación en Ciencias, vol. 6, n. 2, 2011.

CAVAlCANTI, E. L. D.; CARDOSO, T. M. G.; MESQuitA, N. A. S.; SOARES, M. H. F. B. Perfil Químico: debatendo ludicamente o conhecimento científico em nível superior de ensino. Revista Electrónica de Investigación en Educación en Ciencias (En línea), v. 7, p. 73-86, 2012.

CAVALCANTI, E. L. D.; SOARES, M. H.. F. B. S. O uso do jogo de roles (roleplaying game) como estratégia de discussão e avaliação do conhecimento químico. Revista Electrónica de Enseñanza de las Ciencias, vol.8, n.1, 2009.

CAILLOIS, R. Os jogos e os homens: a máscara e a vertigem. Lisboa: Cotovia, 1990.

CHATEAU, J. O jogo e a criança. Guido de Almeida, São Paulo: Summus Editora, p.84, 1984.

CLEOPHAS, M. G. Ensino por investigação: concepções dos alunos de licenciatura em Ciências da Natureza acerca da importância de atividades investigativas em espaços não formais. Revista Linhas, v. 17, n. 34, p. 266-298, 2016.

COSTA, A. A. F.; SOUZA, J. R. T. Obstáculos no processo de ensino e de aprendizagem de cálculo estequiométrico. Amazônia - Revista de Educação em Ciências e Matemática, v.10 (19), p.106-116, 2013.

CUNHA, M. B. Jogos no ensino de química: considerações teóricas para sua utilização em sala de aula. Revista Química Nova na Escola, n. 2, p. 92-98, 2012.

CUNHA, M. B. Jogos de Química: Desenvolvendo habilidades e socializando o grupo. Anais do Encontro Nacional de Estudantes de Química - ENEQ, 2004.

DOMINGOS, D. C. A.; RECENA, M. C. P. Elaboração de jogos didáticos no processo de ensino e aprendizagem de química: a construção do conhecimento. Ciências \& Cognição, v. 15 (1): 272-281, 2010.

FACETOLA, P. B. M.; et al. Os Jogos Educacionais de Cartas como Estratégia de Ensino em Química. Revista Química Nova na Escola, n. 34, N 4, p. 248-255, 2012.

FELÍCIO, C. M. Do compromisso a responsabilidade lúdica: ludismo em ensino de Química na formação básica. Tese de doutorado - Universidade Federal de Goiás, 2011.

FERRER, T. Métodos de enseñanza comunicativos: El juego como estratégia didáctica en la instrucción del español como segunda lengua. Lúdicamente, vol 4, n. 8, 2015.

FIALHO, N. N. Jogos no Ensino de Química e Biologia. Curitiba: IBPEX, 2007.

FREITAS, E.S.; SALVI, R.F. A ludicidade e a aprendizagem significativa voltada para o ensino de geografia. Secretaria do Estado da Educação do Paraná (SEED) - Portal Educacional do Estado do Paraná. Curitiba Artigo do Programa de Desenvolvimento Educacional do Paraná - PDE, 2007. Disponível em: http://www.diaadiaeducacao.pr.gov.br/portals/pde/arquivos/ 894-4.pdf>. último Acesso em: 06 mar. 2017.

GOMES, R. R.; FRIEDRICH, M. A Contribuição dos jogos didáticos na aprendizagem de conteúdos de Ciências e Biologia. In: EREBIO, v.1, p.389-92, 2001. 
GOUVÊA, L. G.; SUART, R. C. Análise das Interações Dialógicas e Habilidades Cognitivas desenvolvidas durante a aplicação de um jogo didático no ensino de química. Ciências \& Cognição, v. 19, n. 1, p. 27-46, 2014.

HESSEL, A. M. D. G. Yuga-yuga: o jogo. In: MIRANDA, H. T.; MENEZES, L. C. (Orgs.). Almanaque de criação pedagógica - A aventura da explicação: ciência e linguagens. Petrópolis: Vozes, 2002. p.20-27.

HUIZINGA, J. Homo ludens: O jogo como elemento de cultura. Trad. J.P. Monteiro. São Paulo: Editora Perspectiva, 1980.

HUIZINGA, J. Homo ludens: o jogo como elemento da cultura. 5 edição. São Paulo: Perspectiva, 2007

JANN, P. N.; LEITE, M. F. Jogo do DNA: um instrumento pedagógico para o ensino de ciências e biologia. Ciências \& Cognição, v.15, n. 1, p. 282-293, 2010.

KISHOMOTO, T. M. Jogo, brinquedo, brincadeira e a educação. São Paulo: Cortez, 183p, 1996.

LACERDA, P. L.; SILVA, A. C. R.; CLEOPHAS, M. G. P. "Dominoando a Química": Elaboração e Aplicação de um Jogo como Recurso Didático para o Ensino de Química. IX Encontro Nacional de Pesquisa em Educação em Ciências - IX ENPEC. Águas de Lindóia, SP, 2013.

LÉVY, P. Collective intelligence: mankind's emerging world in cyberspace. Cambridge: Perseus Books, 1997.

MARTINEZ, E. R. M.; FUJIHARA, R. T.; MARTINZ, C. Show da Genética: um jogo interativo para o ensino de genética. Genética na escola. Botucatu, São Paulo, p. 1-4, 2008.

MESSEDER, H. S.; PINHEIRO, B. C. S.; ROQUE, N. F. Improvisações Teatrais no Ensino de Química: Interface entre Teatro e Ciência na Sala de Aula. Revista Química Nova na Escola, v. 35, n. 2, p. 100-106, 2013.

MIRANDA, A. C. B.; JÓFILI, Z. M. S.; LEÃO, A. M. A. C.; LINS, M. Alfabetização ecológica e formação de conceitos na educação infantil por meio de atividades lúdicas. Investigações em Ensino de Ciências, v. 15, n. 1, pp. 181-200, 2010.

MIRANDA, S. No Fascínio do jogo, a alegria de aprender. In: Ciência Hoje, v.28, 2001 p. 6466.

PIAGET, J. Psicologia da Inteligência. Rio de Janeiro: Zahar, 1977.

PORTO, M. G. C. Jogo, TIC e ensino de química: uma proposta pedagógica. Recife: UFRPE, 2015. 249 f. Tese - Programa de Pós-Graduação em Ensino das Ciências, Universidade Federal Rural de Pernambuco, Recife, 2015.

POUPART, J. et al. A pesquisa qualitativa: enfoques epistemológicos e metodológicos. Tradução Ana Cristina Nasser. Petrópolis: Vozes, 2008. 464 p. Título original: La recherche Qualitative.

RODRIGUES, R. C. B.; FURTADO, W. W. Jogos teatrais no estudo da construção histórica do conhecimento sobre modelos atômicos no ensino fundamental. IX Encontro Nacional de Pesquisa em Educação em Ciências - IX ENPEC. Águas de Lindóia, SP, 2013. 
SÁ, E. F.; PAULA, H. F.; LIMA, M. E. C. C.; AGUIAR, O. G. As características das atividades investigativas segundo tutores e coordenadores de um curso especialização em ensino de ciências. VII E Encontro Nacional de Pesquisa em Educação em Ciências - VII ENPEC. Belo Horizonte-MG, p.01-13, 2007.

SANTOS, A. P. B.; MICHEL, R.C. Vamos jogar SueQuímica? Revista Química Nova na Escola, n. 31, 2009.

SATURNINO, J. C.; LUDUVICO, I.; SANTOS, L. J. Pôquer dos Elementos dos Blocos s e p. Revista Química Nova na Escola, v. 35, n. 3, p. 174-181, 2013.

SILVA, A. C. R.; et al. Importância da Aplicação de Atividades Lúdicas no Ensino de Ciências para Crianças. R. Bras. de Ensino de C\&T, v.8, n.3, p.84-103, 2015.

SOARES, M. H. F. B. e CAVALHEIRO, E.T.G. O ludo como um jogo para discutir conceitos de termoquímica. Revista Química Nova na Escola, n. 23, maio 2006.

SOARES, M. H. F. B. O lúdico em Química: Jogos e atividades lúdicas aplicados ao Ensino de Química. Tese de doutorado, 195 p. São Carlos: UFSCar, 2004.

SOARES, M. H. F. B.; OKUMURA, F.; CAVALHEIRO, E.T.G. Um jogo didático para ensinar o conceito de equilíbrio químico. Química Nova na Escola, n. 18, p. 13-17, 2003.

SOUZA, D. C.; NASCIMENTO JUNIOR, A. F. Jogos didático-pedagógicos ecológicos: uma proposta para o ensino de ciências, ecologia e educação ambiental. In: Anais do V Encontro Nacional de Pesquisa em Educação em Ciências - V ENPEC, 2005, p. 1-12.

TEZANI, T. C. R. O Jogo e os Processos de Aprendizagem e Desenvolvimento: aspectos cognitivos e afetivos. Educação em Revista, v.7, n.1-2, 2006.

TONELLI, M. L. F. Jogos digitais: uma abordagem educacional à luz da Epistemologia Genética. Cadernos de Aplicação, Porto Alegre, v. 24, n. 1, 2011.

VIANA, F. R.; SOUSA, F. E. E. Vamos brincar? As contribuições teóricas de Piaget, Vygotsky e Wallon para o uso de jogos no ensino de matemática. Anais do XI Encontro Nacional De Educação Matemática, CURITIBA, 2013.

VYGOTSKY, L.S. A formação social da mente. In: Interação entre aprendizado e desenvolvimento, $7^{\circ}$ ed. - São Paulo: Martins Fontes, p. 87 - 106, 2007.

VIGOTSKY L. S. Pensamiento y Lenguaje. La Habana, Editorial Pueblo y Educación, 1982.

VYGOTSKY, L. S. et al. Linguagem, desenvolvimento e aprendizagem. São Paulo: Ícone/Edusp, p.103-17, 1988.

VYGOTSKY, L. S. (2004). Psicologia Pedagógica. 2 ed. São Paulo: Martins Fontes.

WALLON, H. As origens do pensamento na criança. São Paulo: Manole, 1989. 